\title{
Avaliação, pelos Estudantes, da Atividade "Trabalho de Conclusão de Curso" como Integralização do Eixo Curricular de Iniciação à Pesquisa Científica em um Curso de Medicina
}

\author{
PALAVRAS-CHAVE: \\ - Educação Médica; \\ - Currículo; \\ - Iniciação Científica; \\ - Pesquisa.
}

KEYWORDS:

- Medical Education;

- Curriculum;

- Scientific Initiation;

- Research.

Recebido em: 24/07/2010

Reencaminhado em: 13/05/2011

Aprovado em: 26/02/2012

\section{Student Evaluation of the Activity - "Research Project for Course Completion" as Final Stage of the Scientific Research Axis in a Medical School}

Hermila Tavares Vilar Guedes ${ }^{I}$ Jorge Carvalho Guedes II

\begin{abstract}
RESUMO
Introdução: $O$ desenvolvimento de um projeto de pesquisa com metodologia adequada proporciona ao aluno a oportunidade de construir competências e habilidades que contribuirão para seu aprimoramento pessoal e, mais tarde, do profissional. Para estar atualizado, este deve ser capaz de buscar conhecimento novo, de qualidade, analisando criticamente a literatura disponível. A prática da pesquisa possibilita a vivência dos aspectos éticos pertinentes à propriedade intelectual è à pesquisa com seres humanos. Objetivo: Conhecer a avaliação que os alunos de graduação em Medicina fazem da atividade de Trabalho de Conclusão de Curso (TCC) como etapa de finalização do eixo curricular de iniciação à pesquisa. Métodos: Estudo qualitativo e quantitativo. Dados quantitativos, que permitem descrever o perfil da amostra, foram coletados por meio de questionários aplicados aos $42(100 \%)$ estudantes da turma inicial de um curso de Medicina que utiliza metodologia ativa de ensino-aprendizagem. Também foram utilizadas informações dos questionários de avaliação desses estudantes, preenchidos pelos 32 orientadores de TCC envolvidos. A abordagem qualitativa envolveu entrevistas realizadas pela internet, com oito estudantes $(19,0 \%)$. Dados quantitativos foram analisados por meio de medidas de tendência central. Na análise dos dados qualitativos, foi utilizada a técnica de Construção do Discurso do Sujeito Coletivo, com base em expressões-chave e ideias centrais recortadas dos discursos individuais. Resultados/Conclusões: A experiência de cursar pesquisa científica, bem como a elaboração do TCC foram consideradas importantes pelos estudantes, tanto para a sua prática enquanto "internos", quanto para a sua vida profissional. Apontam como principais pontos fortes dessa experiência: o desenvolvimento das capacidades de buscar, selecionar e criticar artigos científicos, e o treinamento das habilidades de elaboração de projetos de pesquisa, leitura de artigos em língua estrangeira, análise estatística e apresentação em público.
\end{abstract}

Introduction: The development of a research project - using appropriate methodology — provides students the opportunity to build skills and abilities that will contribute to their personal enrichment and, later on, to their professional. To be up to date, the students must be able to seek new knowledge of quality, critically analyzing the available literature. The practice of research is an opportunity to practice the ethical aspects pertaining to intellectual property and to research with humans. Objective: The aim of this study is to know the evaluation, by the medical students, of the activity Research Project for Course Completion (Trabalho de Conclusão de Curso - TCC) as final stage of the undergraduate research axis. Methods: Quantitative and qualitative research. Quantitative data (which can describe the sample profile) were collected through questionnaires applied to $42(100 \%)$ students in the class of an initial course of medicine that uses active methodology of teaching and learning. - Information from the questionnaires evaluating these students, filled out by the 32 advisors involved in the TCC, was also used. The qualitative approach involved interviews conducted via the Internet, with 8 students (19.0\%). Quantitative data were analyzed using measures of central tendency. The technique for Construction of Collective Subject Discourse from key expressions and main ideas of individual speeches was used for qualitative data analysis. Results/Conclusions: The experiences of scientific initiation and of developing their project were considered important by the students, both for their practice as "interns", as for their professional lives. They indicated that the main strengths of these experiences were: to develop the abilities to search, select and critique scientific articles; to get skills for research projects preparation, reading papers in foreign languages, statistical analysis and public presentation.

${ }^{I}$ Faculdade de Tecnologia e Ciências de Salvador, Salvador, BA, Brasil.

"I Universidade Federal da Bahia, Faculdade de Medicina, Salvador, BA, Brasil; Faculdade de Tecnologia e Ciências de Salvador, Salvador, BA, Brasil 


\section{INTRODUÇÃO}

\section{O Médico: um Profissional Permanentemente em Formação}

O progresso das Ciências da Saúde e o número crescente de comunicações científicas configuram uma dificuldade para a atualização contínua do médico. A leitura de compêndios deixou de ser a forma ideal de atualização, uma vez que, por questões operacionais, estes dependem de um tempo longo até serem publicados. Já os artigos científicos, sobretudo nos periódicos de divulgação eletrônica, são publicados mais rapidamente, tornando acessíveis os novos conhecimentos. Alguns autores chegam a considerar os livros técnicos obsoletos $^{1}$. Para estar permanentemente atualizado, o médico precisa saber ler e avaliar artigos científicos, a fim de ter acesso às informações mais recentes.

Sendo assim, é necessário instrumentar os futuros médicos, para que busquem, nas fontes mais atualizadas, os novos conhecimentos que vão surgindo. Para isso, esses profissionais devem ser capazes de analisar criticamente um texto científico do ponto de vista metodológico, a fim de agregar as conclusões adequadamente estabelecidas e utilizá-las como base para a sua prática profissional, e de rejeitar as conclusões obtidas inadequadamente. Essa é a essência da chamada "Medicina Baseada em Evidências" (MBE), definida por Heneghan e Badenoch como "o uso consciente, explícito e judicioso da melhor evidência atual na tomada de decisões sobre pacientes individuais" $^{\prime 2}$ (p. 8). Ou seja, exercer a Medicina Baseada em Evidências significa considerar a experiência clínica individual do profissional e integrá-la à melhor evidência clínica externa disponível, obtida por meio de pesquisa científica ${ }^{1}$.

Assim, a ênfase nas metodologias ativas de "ensinagem" na área de saúde, notadamente crescente em cursos de Medicina, precisa abranger o desenvolvimento da "criticidade científica". É necessário, então, conhecer os processos de aquisição do conhecimento, a fim de avaliar a adequação de métodos e técnicas de pesquisa e, consequentemente, a validade de suas conclusões. A necessidade de elaborar um Trabalho de Conclusão de Curso (TCC) tem, nessa análise sumária, a sua justificativa.

\section{A Prática da Pesquisa Científica na Formação do Estudante}

Pesquisar um tema envolve a busca do conhecimento mais recente sobre o assunto e a construção das chamadas "questões de pesquisa" e de um projeto concebido de modo que permita encontrar respostas a essas indagações. As tarefas necessárias para desenvolver um projeto, planejadas e executadas de acordo com o método adequado, culminando com a discussão dos resultados e a elaboração das conclusões do estudo, são cami- nhos que conduzem a um desenvolvimento considerável de diversas habilidades cognitivas e emocionais.

Para realizar um trabalho de pesquisa, é necessária boa dose de perseverança e muito compromisso com o trabalho, executando-se cada etapa metodológica de forma correta. Um estudo científico pode ter resultados esperados ou não, positivos ou negativos em relação a determinada demanda. Os resultados serão sempre válidos se foram utilizados os métodos adequados de realização e de análise. Essas afirmações levam o orientador atento e também o supervisor de pesquisa na graduação a demonstrar o paralelismo nas linhas de atitudes do aluno enquanto pesquisador sério e ser humano ético. Entre as qualidades que um bom médico deve ter, estão aquelas atribuídas ao bom pesquisador, ou seja: deve ser minucioso, detalhista na coleta e na análise de dados e ter a capacidade de pensar além de ideias estabelecidas. Deverá discutir seus resultados, situá-los dentro do conhecimento existente e encontrar a verdadeira utilidade de suas conclusões ${ }^{3}$.

Adquirindo habilidades para buscar o conhecimento mais recente sobre determinado tema por meio da pesquisa científica, os estudantes exercitam a criatividade e começam a ter ideias para estudos. Estimular a descoberta da capacidade do aluno e apoiar essas iniciativas são ações que constituem um método de atuação do professor de iniciação científica. Esse método contraria a prática frequente de atribuir ao estudante tarefas planejadas por outrem, para que ele as execute sem ter raciocinado sobre a necessidade ou a forma de realizá-las e, também, sem avaliar o impacto de sua participação no estudo sobre a sua formação profissional. Concordando com Foucault $^{4}$, podemos dizer que o aprendizado por meio de uma experiência não implica que esta deve ser repetida, mas, sim, que deve ser revisada, repensada e recriada, já que experimentar é um ato de abertura que, per si, denota transformação.

Vários estudos têm avaliado o desempenho de estudantes que utilizam a Medicina Baseada em Evidências (MBE) (Evidence-Based Medicine - EBM), algumas vezes comparando currículos diferentes, todos resultando na convicção de que se trata de valiosa contribuição para a formação do médico ${ }^{5-8}$.

Jacobs e Cross ${ }^{9}$, em 1995, publicaram a análise da experiência de iniciação científica da Universidade de Stanford. Foi evidenciado que, vários anos após a conclusão dos cursos, os profissionais que participaram de grupos de pesquisa durante a graduação tendem a sobressair no mercado de trabalho, mesmo quando não continuam com atividades de pesquisa. Características como maior capacidade de se expressar com base em informações sólidas e maiores capacidades de análise e de leitura de artigos científicos teriam sido decisivas para esse sucesso. 


\section{A Pesquisa Científica nos Currículos das Escolas Médicas}

Os programas curriculares de pesquisa científica no curso médico estão presentes em países como Canadá, Estados Unidos e Inglaterra há vários anos. Esta presença tornou-se mais significativa após a introdução do chamado Aprendizado Baseado em Problemas (Problem Based Learning - PBL), pois a necessidade de pautar a conduta clínica em evidências científicas conduziu à MBE, cujo significado foi abordado no início do presente texto.

No Brasil e em outros países, a pesquisa científica como parte da formação médica tornou-se mais presente a partir da década de $1930^{10}$. Contudo, a iniciação científica passou a ser um especial objeto de reflexão pedagógica na década de 1990, quando surgiu a discussão sobre a proposta de torná-la uma disciplina ${ }^{11,12}$. Há relato sobre o começo da iniciação científica curricular na Faculdade de Medicina da Universidade Federal Fluminense ter ocorrido em $1995^{13}$; contudo, a maior parte dos artigos publicados na década de 1990 versa sobre a importância de envolver os estudantes em pesquisas, sem considerar esta atividade como uma obrigação curricular.

Ainda hoje, embora algumas escolas médicas adotem disciplinas de pesquisa científica em suas grades curriculares, é comum que elas sejam oferecidas com duração de um semestre. Na maioria das vezes, o conteúdo programático se resume à apresentação de modelos formais a serem seguidos para a realização de trabalhos, os quais seriam úteis para a elaboração de monografias, na formatação de revisões de tema, aceitas pelas escolas como um Trabalho de Conclusão de Curso.

Um recente estudo compilou as opiniões de 413 estudantes de seis cursos de Medicina sediados em quatro Estados brasileiros e mostrou que $84 \%$ do grupo estudado defendiam a inclusão da iniciação à pesquisa como atividade curricular obrigatória nos cursos médicos, enquanto apenas 7\% declararam não ter interesse por pesquisa. Tal estudo demonstrou que existe um entendimento acerca da importância do binômio ensino-pesquisa e que há uma expectativa no sentido de que haja uma determinação oficial nessa direção ${ }^{14}$.

\section{O Trabalho de Conclusão de Curso e as diretrizes do Ministério da Educação para os cursos médicos}

Acreditando no impacto positivo que a iniciação à pesquisa científica pode exercer sobre a formação do estudante, o Ministério da Educação (MEC) incluiu, nas Diretrizes Curriculares Nacionais para Cursos de Graduação em Medicina, aprovadas em 2001, referências a este aspecto da formação médica ${ }^{15}$ :

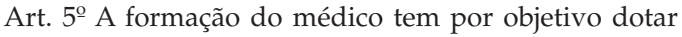
o profissional dos conhecimentos requeridos para o exercício das seguintes competências e habilidades específicas:

$\mathrm{XV}$ — conhecer os princípios da metodologia científica, possibilitando-lhe a leitura crítica de artigos técnico-científicos e a participação na produção de conhecimentos;

Art. 8o O projeto pedagógico do Curso de Graduação em Medicina deverá contemplar atividades complementares e as Instituições de Ensino Superior deverão criar mecanismos de aproveitamento de conhecimentos, adquiridos pelo estudante, mediante estudos e práticas independentes, presenciais e/ou a distância, a saber: monitorias e estágios; programas de iniciação científica; programas de extensão; estudos complementares e cursos realizados em outras áreas afins.

Art. 9ำ O Curso de Graduação em Medicina deve ter um projeto pedagógico, construído coletivamente, centrado no aluno como sujeito da aprendizagem e apoiado no professor como facilitador e mediador do processo ensino-aprendizagem. Este projeto pedagógico deverá buscar a formação integral e adequada do estudante por meio de uma articulação entre o ensino, a pesquisa e a extensão/assistência.

Art. 12. A estrutura do Curso de Graduação em Medicina deve:

II - utilizar metodologias que privilegiem a participação ativa do aluno na construção do conhecimento e a integração entre os conteúdos, além de estimular a interação entre o ensino, a pesquisa e a extensão/assistência;

Ao valorizarem a iniciação científica na graduação, as Diretrizes Curriculares Nacionais incentivam de forma quase direta a elaboração de TCC, cuja inclusão na grade curricular passou a ser uma recomendação importante para que o curso obtenha avaliação positiva do MEC. Contudo, o TCC não é obrigatório em todos os cursos de Medicina no Brasil. Entre os cursos que adotam tal prática, muitos aceitam uma revisão simples de tema médico como suficiente para a atribuição de nota e aprovação.

\section{O Eixo de Iniciação à Pesquisa Científica no Curso de Medicina em Foco}

O presente estudo foi desenvolvido em um curso de Medicina pertencente a uma instituição privada, sediada em Salvador (BA), que iniciou suas atividades em 2005. O projeto peda- 
gógico do curso (PPC) utiliza técnicas como o Aprendizado Baseado em Problemas e a simulação, adaptadas com base em observações e discussões. A experiência de construção do curso vem sendo continuamente aperfeiçoada pelo grupo de docentes, tendo por base os resultados observados.

Entre as inovações integrantes do PPC, destaca-se o eixo curricular de iniciação à pesquisa científica. Trata-se de um núcleo longitudinal de disciplinas que conduzem o estudante a elaborar um Trabalho de Conclusão de Curso, terminado antes do início de suas atividades específicas de "internato", nos quatro últimos semestres do curso.

A pesquisa científica é oferecida como atividade curricular desde o primeiro semestre, visando estimular a curiosidade e o interesse dos estudantes pela busca do próprio conhecimento.

A abordagem do conteúdo da disciplina, em cada semestre, é permeada pelo trabalho com artigos científicos em classe, versando, preferencialmente, sobre temas em discussão nas sessões tutorais, além de outros, pertinentes ao conteúdo do semestre.

No quinto semestre, a construção do projeto do Trabalho de Conclusão de Curso é tarefa obrigatória. Tal projeto deve ser elaborado ou reconstruído a partir de projetos construídos em semestres anteriores, de modo que a sua apresentação, com a formatação recomendada pelo curso, constitui o trabalho de finalização da disciplina.

As tarefas de desenvolvimento do TCC são efetuadas sob orientação de um docente do curso, sendo facultada a orientação por um profissional externo, desde que haja a coparticipação de um docente do curso. Para integrar o cadastro de orientadores, é necessário possuir título de mestre ou doutor, ou produção científica comprovada.

Diferindo da orientação dos TCC pelos docentes orientadores, a qual deve começar logo que o estudante defina seu tema e/ou projeto, a função de supervisão do Trabalho de Conclusão de Curso assume seu papel no sétimo e no oitavo semestres. A supervisão tem como pressuposto a avaliação contínua do processo, a qual é mais importante do que a avaliação dos produtos, já que é construindo e reconstruindo alicerces que a atividade pode ser continuamente aperfeiçoa$\mathrm{da}$, fortalecendo-se como um dos eixos principais do projeto pedagógico do curso de Medicina em foco.

No decorrer do sétimo semestre, os trabalhos são apresentados em classe, configurando o desenvolvimento da disciplina Trabalho de Conclusão de Curso. O objetivo dessas apresentações é possibilitar que a supervisão do TCC perceba o desenvolvimento das tarefas e, se necessário, sugira modificações ou adaptações.

Durante o oitavo semestre, a disciplina Trabalho de Conclusão de Curso tem continuidade. Nesse momento, as apresentações dos trabalhos já mostram resultados e, muitas vezes, também discussão e conclusões. Trata-se de uma preparação para a apresentação feita a uma banca composta por três membros - de preferência, um membro externo e dois docentes do curso - em sessões especialmente programadas.

Entre os pontos básicos no regulamento do TCC, destacam-se os seguintes: o trabalho deve ter a autoria do estudante. Quando um aluno inicia sua participação em um estudo de autoria de seu orientador, já em andamento, deverá observar algumas determinações a fim de que possa utilizar esta participação como TCC. O projeto apresentado pelo estudante deve estar contido no projeto geral do estudo; e o aluno deve ter participação na fase de execução e não apenas de construção do banco de dados e da análise estatística. Além disso, a redação de cada parte do TCC apresentado deve ser de sua autoria. Tais preocupações se justificam porque é necessário que o estudante vivencie cada etapa do processo de construção do conhecimento, a fim de que possa compreender, valorizar e criticar artigos científicos. Dessa forma, atualizar-se por meio da leitura de artigos poderá ser um hábito do futuro profissional.

O objetivo geral deste estudo foi conhecer as opiniões dos estudantes da turma inicial (2005) do curso em foco sobre a atividade "Trabalho de Conclusão do Curso" (TCC) como tarefa de finalização do eixo curricular de pesquisa científica no curso de graduação em Medicina.

\section{METODOLOGIA}

Trata-se de um estudo transversal de metodologia mista quantitativa e qualitativa. O universo amostral foi composto por 42 estudantes matriculados no décimo semestre do curso de Medicina da Faculdade de Tecnologia e Ciências (FTC). Esses estudantes compõem a turma que iniciou o curso no primeiro semestre de 2005. Para as questões que envolvem orientadores, foram considerados os 32 docentes do quadro funcional da FTC ou preceptores externos, que atuaram como orientadores dos alunos da turma estudada.

As seguintes questões nortearam o desenvolvimento do presente estudo:

1. A experiência de cursar as disciplinas curriculares do eixo de pesquisa científica, culminando com a elaboração do TCC, é considerada importante pelos estudantes?

2. Quais os aspectos identificados pelos estudantes como "pontos fortes" dessa experiência?

3. Quais os aspectos identificados pelos estudantes como "pontos fracos" dessa experiência?

4. Os estudantes percebem alguma influência da experiência de elaboração do TCC sobre o seu desempenho no internato? 
5. Os atuais "internos" vislumbram alguma influência da experiência de elaboração do TCC na sua futura prática profissional? Em que habilidade(s) essa influência ocorreria?

6. Qual a média de pontuação atribuída pelos orientadores aos estudantes em cada um dos diferentes critérios avaliados (interesse, quantidade de trabalho, conhecimento sobre a metodologia aplicada, capacidade de organização, iniciativa e disponibilidade para realizar as tarefas)?

7. Qual a média de pontuação atribuída pelos estudantes aos orientadores nos itens: interesse, conhecimento do assunto do trabalho, apresentação de sugestões sobre o desenvolvimento do trabalho, disponibilidade para reuniões e tarefas?

Foram incluídos no estudo os alunos matriculados no oitavo semestre do curso de Medicina durante o período letivo de 2008.2 que devolveram o questionário de avaliação, aplicado na época da finalização do TCC, devidamente preenchido, e que estavam cursando o internato curricular do nono semestre em 2009. ${ }^{1}$

Para atender à abordagem quantitativa, foram utilizadas as informações constantes nos questionários aplicados à totalidade de alunos e de orientadores envolvidos, no momento da entrega dos trabalhos de conclusão de curso, no final do oitavo semestre, como instrumento de avaliação da disciplina. Tais informações compõem um banco de dados construído em arquivo SPSS, utilizado na análise estatística.

O terceiro instrumento utilizado foi uma entrevista feita através da internet, encaminhada ao mesmo grupo de estudantes no final do nono semestre letivo (internato I), especificamente para integrar o presente estudo.

A análise quantitativa foi utilizada para descrever o grupo estudado, bem como para apresentar opiniões diretas e pontuais sobre assuntos relativos ao tema.

A metodologia qualitativa foi empregada para permitir entender e descrever o pensamento do conjunto de estudantes dessa turma inicial sobre o eixo de PC no curso. A análise qualitativa envolveu apenas os oito estudantes (19,0\%) que responderam ao total de três mensagens enviadas por via eletrônica, convidando a todos para participar da segunda etapa do estudo. Esses estudantes responderam a seis questões abertas (Quadro 1).

Para a análise, as respostas dos estudantes a cada questão foram reunidas sob a forma de tabelas, categorizadas a partir de palavras ou termos utilizados na redação, identificados como "termos indicadores". Este procedimento metodológico corresponde à técnica denominada "Discurso do Sujeito Coletivo" $(\mathrm{DSC})^{16}$. Por meio dessa técnica, as opiniões individuais acerca de cada aspecto são reunidas de modo a construir um texto que retrate o pensamento coletivo sobre cada questão específica.
QuAdRo 1.

Questões que compuseram as entrevistas via Internet

1.Você poderia dizer qual a sua impressão sobre a experiência de realização do seu TCC?

2.Você acredita que o fato de ter elaborado o seu TCC está influindo na sua prática do Internato em medicina?

3.Você acredita que essa experiência irá exercer alguma influência na sua futura prática profissional?

4.Quais os pontos positivos que você aponta na experiência de ter cursado o eixo de Pesquisa Científica na sua Graduação?

5.E quais os pontos negativos?

6.O que você acredita que pode melhorar? Teria sugestões?

Os "termos indicadores", chamados por Levèvre de "expressões-chave", são recortes do discurso, os quais demonstram pontos essenciais da opinião do entrevistado ${ }^{16}$. O agrupamento das expressões-chave encontradas nas respostas de cada indivíduo entrevistado forma uma "ideia central". Assim, a agregação das expressões-chave em ideias centrais corresponde a uma categorização das respostas, que, compiladas, caracterizam o discurso coletivo.

Todos os estudantes estavam cientes da utilização de seus questionários para a elaboração de estudos, sem identificação. Foi feito um convite formal, e nenhum deles se manifestou contrário à participação.

\section{RESULTADOS E DISCUSSÃO}

Todos os 42 estudantes integrantes da turma inicial do curso responderam ao questionário, assim como todos os 32 orientadores envolvidos.

Dentre os 42 estudantes, 16 (38,1\%) realizaram Trabalhos de Conclusão de Curso sobre temas de Clínica Médica. A segunda área mais frequentemente escolhida foi Cirurgia (sete estudantes; $16,7 \%$ ); seguida por Saúde Mental e Obstetrícia/ Ginecologia, com seis estudantes (14,3\%). Observa-se que, apesar de apenas um estudante ter seu trabalho classificado como pertencente às áreas de Saúde Coletiva e Epidemiologia, vários deles utilizaram metodologia epidemiológica para trabalhar os temas escolhidos.

Analisando o período em que ocorreu o início da orientação para o TCC, observamos que, para 35,7\% dos estudantes, este início aconteceu no quinto semestre. Ressaltamos que no final do quinto semestre os estudantes devem apresentar seus projetos de TCC. Para 33,3\% da turma, o início da orientação ocorreu no oitavo semestre do curso. Esse dado pode indicar que é elevado o número de estudantes que atrasou o início de seu trabalho até o semestre no qual deveria finalizar o estudo, abreviando o tempo utilizado para a tarefa. 
Trinta e quatro estudantes $(81,0 \%)$ informaram ter submetido seu projeto de TCC a um Comitê de Ética em Pesquisa (CEP). Essa informação estava ausente em três questionários $(7,1 \%)$. Cinco estudantes $(11,9 \%)$ informaram que a questão não se aplica (porque o estudo integrava um projeto maior, já autorizado, ou se tratava de revisão sistemática, que utiliza dados secundários, dispensando a aprovação pelo CEP). Dentre os estudos que haviam sido aprovados por um CEP, $25(59,5 \%)$ tramitaram na própria instituição e nove $(21,4 \%)$ em outro CEP, na instituição onde ocorreu a coleta de dados.

As avaliações dos orientadores sobre a elaboração dos trabalhos de TCC consideraram sete aspectos: interesse demonstrado (média da turma $=4,2$ ); quantidade de trabalho realizado (média da turma $=4,0$ ); conhecimento do assunto (média da turma $=4,0)$; conhecimento da metodologia empregada no estudo (média da turma $=3,6$ ); capacidade de organização (média da turma $=4,0$ ); iniciativa e disponibilidade para as tarefas correspondentes ao trabalho (média da turma $=4,3$ ). Foi observado que em seis critérios a maioria dos estudantes obteve o escore máximo (5), enquanto na avaliação do conhecimento em metodologia da pesquisa a "moda" do escore foi 4. Contudo, em todos os critérios, a maioria absoluta dos estudantes obteve escores 4 ou 5, caracterizando um resultado bastante satisfatório. Contudo, três $(7,1 \%)$ estudantes obtiveram escore zero em todos os critérios.

Quanto à avaliação dos orientadores, 32 (76,2\%) estudantes atribuíram escores, sendo que $47,6 \%$ atribuíram o escore máximo (5) ao seu orientador, enquanto $23,8 \%$ atribuíram o escore 4 . Apenas 4,8\% atribuíram escore 2 ao orientador. A média de pontuação atribuída pelos estudantes aos orientadores, considerando os itens interesse, conhecimento do assunto do trabalho, apresentação de sugestões sobre o desenvolvimento do trabalho, disponibilidade para reuniões e tarefas, foi igual a 4,6.

No final do oitavo semestre, 37 (88,1\%) estudantes apresentaram seus trabalhos à banca e foram aprovados. No entanto, dois alunos $(4,8 \%)$ foram reprovados e três $(7,1 \%)$ não haviam concluído seus trabalhos no prazo definido.

Utilizando metodologia qualitativa, interpretamos os discursos dos estudantes envolvidos no estudo, construindo, assim, o Discurso do Sujeito Coletivo, com base em seis questões (vide abaixo), sendo que para cada uma delas foi elaborada uma resposta composta pelos discursos do conjunto de entrevistados.

\section{Questões que Compuseram as Entrevistas via Internet}

1. Você poderia dizer qual a sua impressão sobre a experiência de realização do seu TCC?

2. Você acredita que o fato de ter elaborado o seu TCC está influindo na sua prática do internato em Medicina?
3. Você acredita que essa experiência irá exercer alguma influência na sua futura prática profissional?

4. Quais são os aspectos positivos que você aponta na experiência de ter cursado o eixo de pesquisa científica na sua graduação?

5. E quais são os pontos negativos?

6. O que você acredita que pode melhorar? Teria sugestões?

\section{Compilação das Respostas Obtidas}

Na opinião do grupo, a experiência foi válida. Os estudantes afirmam que aproveitaram a experiência de elaboração de uma pesquisa científica.

Há o reconhecimento de que a experiência de haver cursado pesquisa científica na graduação foi importante, de forma que o grupo estudado a qualifica positivamente.

Em vários trechos dos discursos individuais, os estudantes se mostram gratificados pelo esforço de realizar o TCC:

\author{
"Conseguimos produzir muita coisa interessante" \\ "Acabei gostando muito e me orgulho de ter feito" \\ "Foi uma experiência minha mesmo, a elaboração do TCC" \\ "Aprendi com esse trabalho como é importante a pesquisa \\ científica e como é gratificante ver o resultado final" \\ "Colocar em prática aquilo que se vê em aula sempre torna as \\ coisas mais interessantes, apesar das dificuldades vivenciadas \\ durante a produção do TCC"
}

\section{O TCC foi trabalhoso}

A elaboração do TCC demanda esforço, tendo sido considerada "trabalhosa". Contudo, há o reconhecimento da importância da experiência vivida, como descrito acima.

Ressaltamos um trecho retirado de um discurso individual:

\footnotetext{
"Antes de iniciar o trabalho, e, mais ainda, antes do contato acadêmico com pesquisa científica, enxergava o TCC como uma dificultosa tarefa obrigatória para a formação universitária... Realmente é bastante trabalhoso, mas adquiri conhecimento e ferramentas que serão de grande utilidade na minha vida profissional."
}

De fato, a importância de compreender o processo de construção do conhecimento tem sido percebida por estudantes e educadores em diversas áreas. Contudo, muitas vezes, essa percepção não é aprofundada em aspectos menos nucleares, como o caráter instrumental da disciplina Pesquisa Científica. Alguns estudantes, em seu discurso, reconhecem 
que adquiriram "ferramentas" relevantes para a sua prática, enquanto outros deixam dúvida quanto a terem adquirido consciência sobre as capacidades que o treinamento em pesquisa pode desenvolver.

\section{Concluído o Trabalho, a Percepção dos Estudantes sobre a Experiência é Positiva}

A satisfação por concluir o trabalho é uma característica evidente. Os estudantes apresentam sentimentos de orgulho por terem concluído o trabalho e de estímulo para realizar novos estudos.

A percepção de que possuem a capacidade de desenvolver uma pesquisa com características científicas parece ser um poderoso estímulo ao esforço, ao estudo, à iniciativa. Observamos que muitos alunos passam a se destacar nas tarefas do curso após perceberem a própria capacidade de criar e executar um projeto.

\section{Não há consenso sobre a influência do TCC no internato}

Embora a maioria dos estudantes perceba a influência benéfica que a experiência de desenvolver uma pesquisa exerce sobre seu desempenho, inclusive nas atividades do internato, essa percepção não é consensual. Alguns discursos concatenam as habilidades desenvolvidas ao realizar uma pesquisa com a rotina da atenção direta ao paciente, como ocorre no internato.

Dentre os discursos individuais, destacamos o trecho seguinte:

"Bons internatos fundamentam suas discussões na chamada Medicina Baseada em Evidências, a qual não é possível praticar sem uma análise critica dos fatos. A necessidade de elaborar um bom TCC nos fornece parte dessa capacidade de análise"

Tal discurso mostra a maturidade intelectual do estudante, quase médico, que não aceitará seguir protocolos sem analisar a validade das informações que os baseiam.

\section{A Influência da Experiência do TCC na Futura Prática Profissional é Considerada Positiva}

A influência da realização do TCC na futura prática profissional tem como fundamento o reconhecimento da necessidade de atualização permanente. Também há a consciência de que a capacidade crítica desenvolvida será de grande valor para tomar decisões médicas, como citado no item anterior.

\section{Existe uma Clara Percepção de Pontos Positivos na} Experiência Deste Grupo ao Cursar Pesquisa na Graduação Os pontos positivos mais indicados são o desenvolvimento de várias capacidades importantes: buscar, selecionar e criticar artigos científicos; as habilidades na apresentação de temas e na leitura de artigos em língua estrangeira; o treinamento em elaboração de projetos de pesquisa e em análise estatística. Também são evidenciados outros aspectos positivos, como o fato de o envolvimento com pesquisa proporcionar contatos profissionais potencialmente importantes.

No entanto, ressaltamos duas observações colhidas dos discursos individuais:

\section{"Aprendi que qualquer pessoa pode realizar uma pesquisa." \\ "Foi muito bom aprender todos os passos para a elaboração de um trabalho de pesquisa... Até a finalização do trabalho, ou melhor, a conclusão de uma parte do trabalho; afinal, é muito difícil esgotar todos os pontos de uma pesquisa."}

O discurso acima traduz a compreensão sobre a relatividade da verdade científica, a qual se complementa a cada nova questão de pesquisa que surge após a conclusão (ou não) de um estudo.

\section{Há Alguns Pontos Apontados como Negativos}

Na percepção dos estudantes, alguns aspectos negativos influenciam a experiência do eixo curricular da pesquisa na graduação. As queixas indicam insatisfações que podem ser classificadas em três tipos: problemas de infraestrutura; problemas de ordem administrativa e/ou pedagógica; e problemas que podem estar diretamente relacionados à forma como o aluno se localiza no curso e nas atividades de pesquisa e TCC.

Dentre os problemas de infraestrutura, são apontadas deficiência na quantidade de livros sobre elaboração de pesquisa e necessidade de programas estatísticos específicos. Quanto aos problemas pedagógicos, alguns são relacionados ao curso, como deficiências no módulo de Estatística (alocação da disciplina em época precoce na grade curricular). Tal fato merece uma explanação: a turma em estudo, sendo a primeira a iniciar o curso, foi alvo de algumas experiências que mostraram, depois, necessidade de adequação. Em vários momentos, os discursos dos entrevistados abordam essa característica. Assim, nas disciplinas de Pesquisa Científica I e II (respectivamente no primeiro e no segundo semestres), o conteúdo programático necessitou ser revisado, de modo que a experiência da presente turma influenciou as modificações que se sucederam. Acreditamos que este é um dos motivos pelos quais alguns entrevistados se referem a especificidades da turma durante seu curso.

As discussões sobre metodologia nas sessões clínicas, nos semestres mais adiantados, procuraram suprir a deficiência gerada pela abordagem precoce de Estatística, sem a ênfase 
necessária na Metodologia Científica. Outro problema da esfera pedagógica identificado neste estudo diz respeito a orientadores que não estariam se empenhando nessa função.

A referência a questões administrativas, como "prazos curtos" e "mudanças repentinas de cronograma", decorre de interpretações muito específicas. A demanda por muito tempo e esforço, observada em alguns trechos dos discursos analisados, pode ter influenciado o pensamento do entrevistado, uma vez que não houve, segundo a análise descritiva dos dados quantitativos, atraso na finalização dos trabalhos para a grande maioria dos estudantes dessa turma. Há, também, referência a suposta falta de organização para as sessões de apresentação dos TCC.

Há, ainda, críticas à instituição, as quais apontam uma suposta falta de reconhecimento das especificidades do curso de Medicina, e, também, referência a "ausência de linhas de pesquisa da própria faculdade voltada para o curso de Medicina e com recursos financeiros".

\section{Sugestões para Melhorar o Eixo de Pesquisa no Curso}

Apresentam-se a seguir as sugestões oferecidas para melhorar o eixo de pesquisa científica e as atividades de TCC no curso de Medicina da FTC, sendo assinaladas as já implementadas e aquelas em fase de encaminhamento:

- Apresentar cronograma com a programação de todas as atividades de pesquisa, informando prazos até o final do TCC para cada turma, no início do curso (em encaminhamento);

- Nas aulas de pesquisa, utilizar artigos que versem não apenas sobre o caso clínico da semana ou seu diagnóstico diferencial, mas sobre temas de outras disciplinas, além das sessões tutoriais (sugestão implementada);

- Colocar os conteúdos de Bioestatística nos semestres mais avançados (sugestão implementada);

- Promover capacitação de orientadores (sugestão implementada);

- Alocar professores de pesquisa com carga horária exclusiva para orientação;

- Incentivar a produção científica;

- aumentar o número de bolsas Pibic para o curso de Medicina;

- oferecer bolsas aos melhores TCC, mediante concurso;

- montar laboratórios avançados de pesquisa;

- incentivar a criação de mais linhas de pesquisa;

- Realizar as apresentações de TCC em conjunto, no auditório (em encaminhamento).

\section{CONCLUSÕES}

Os alunos consideram importante a experiência de cursar as disciplinas curriculares do núcleo de pesquisa científica, bem como a elaboração do TCC, para o seu desempenho como estudante e como profissional, no futuro. Também reconhecem as capacidades desenvolvidas por meio da atividade de pesquisa e da realização do TCC.

Como "pontos fortes" dessa experiência, os estudantes identificam:

- desenvolvimento das capacidades de buscar, selecionar e criticar artigos científicos;

- treinamento das habilidades de apresentação de temas e de leitura de artigos em língua estrangeira;

- treinamento em elaboração de projetos de pesquisa e em análise estatística;

- contatos profissionais potencialmente importantes.

Os estudantes apontam os seguintes "pontos fracos" dessa experiência:

- deficiência na quantidade de livros sobre elaboração de pesquisa;

- necessidade de programas estatísticos específicos;

- alocação precoce do conteúdo de Estatística na grade curricular da turma;

- problemas com orientadores;

- dispêndio de tempo para as tarefas do TCC;

- carência de infraestrutura para pesquisa e de incentivos institucionais.

Os estudantes percebem a influência da experiência de elaboração do TCC sobre seu desempenho no internato. Contudo, essa percepção não é consensual.

Os atuais "internos" percebem, de forma clara, a influência da experiência de elaboração do TCC na futura prática profissional. Tal influência reside na capacidade de atualização permanente e de exercer a Medicina Baseada em Evidências.

As médias atribuídas pelos orientadores aos estudantes nos critérios avaliados demonstram aproveitamento satisfatório.

A média de pontuação atribuída pelos estudantes aos orientadores foi igual a 4,6, considerando os itens interesse, conhecimento do assunto do trabalho, apresentação de sugestões sobre o desenvolvimento do trabalho e disponibilidade para reuniões e tarefas. Os orientadores de 32 estudantes foram avaliados, enquanto dez estudantes não preencheram a avaliação.

Do total de 42 estudantes, 37 (88,1\%) apresentaram seus trabalhos às bancas e foram aprovados. Dois alunos $(4,8 \%)$ fo- 
ram reprovados e três $(7,1 \%)$ não haviam concluído seus trabalhos no prazo determinado.

\section{FINALIZANDO...}

A opinião dos estudantes (reação/grau de satisfação) é o primeiro degrau de avaliação de experiências pedagógicas na Escala de Kirkpatrick ${ }^{17}$. Afinal, o aluno é a razão da existência do curso de graduação e, enquanto consciente da necessidade de desenvolver suas habilidades, é o mais importante elemento no processo ensino-aprendizagem.

A apreciação feita pelos estudantes entrevistados mostra que a implantação da iniciação científica curricular no curso de Medicina da FTC constitui uma experiência exitosa. O discurso coletivo construído com base nas entrevistas individuais indica que os estudantes reconhecem o valor da pesquisa científica curricular, cujas atividades se encerram com a elaboração e apresentação dos trabalhos. Mais que isso, foi observado um sentimento de satisfação pela realização do TCC, embora considerada trabalhosa.

A necessidade de estímulo institucional, a falta de docentes capacitados e com carga horária destinada à orientação de estudantes em atividades de iniciação científica, bem como as deficiências de infraestrutura, apontadas por nossos estudantes, são problemas também citados em outros estu$\operatorname{dos}^{14}$. No entanto, nossa experiência mostra que é possível caminhar

O presente estudo deverá ter continuidade, no intuito de verificar não apenas o conhecimento sedimentado do conteúdo programático do eixo de iniciação à pesquisa, mas também a importância prática que esse conhecimento e a experiência de desenvolver o TCC estarão exercendo na vida profissional desses atuais estudantes.

Na construção de melhores formas de proceder, é imprescindível socializar o conhecimento adquirido pela experiência. Dessa forma, alargam-se as possibilidades de desenvolver alternativas específicas, a serem aplicadas nas diferentes instituições. É preciso conhecer pontos positivos e negativos de experiências anteriores, a fim de subsidiar avanços metodológicos. A multiplicação de possibilidades que ocorre a partir de uma experiência divulgada cria elos entre os indivíduos interessados no tema, de modo que todos poderão trabalhar conjuntamente, na direção do novo, do melhor.

Projeto aprovado pelo Comitê de Ética em Pesquisa da Somesb-FTC (Parecer nํ 0375/2008 registro CEP: 345-2008).

\section{REFERÊNCIAS}

1. Sackett DL, Straus SE, Richardson WS, Rosemberg WMC, Heynes RB. Evidence Based Medicine: How to practice and teach EBM. 2 ${ }^{\mathrm{a}}$ Ed. New York: Churchill Livingstone, 2000. 261p.

2. Heneghan C, Badenoch D. Definição de Medicina baseada em evidências. In: Ferramentas para a Medicina Baseada em Evidências. 2ª Ed. Porto Alegre: Artmed 2007.

3. Guedes HTV. Uma Introdução à Pesquisa Científica. Rev Baiana Pediatr 2006; 2(1): 56-9.

4. Foucault M. Dits et Ecrits. Paris: Gallimard,1975. Disponível em: http://www.4shared.com/file/58448343/7e7324a8/ Foucault_dits_et_ecrits_II_1970-1975.html. Acesso em 23.06.2009.

5. Holloway R, Nesbit K, Bordley D, Noyes K. Teaching and evaluating first and second year medical students' practice of evidence-based medicine. Med Educ. 2004;38(8):868-78.

6. Forjuoh SN, Rascoe TG, Symm B, Edwards JC. Teaching medical students complementary and alternative medicine using evidence-based principles. J Altern Complement Med. 2003 Jun;9(3):429-39.

7. Srinivasan M, Weiner M, Breitfeld PP, Brahmi F, Dickerson KL, Weiner G. Early introduction of an evidence-based medicine course to preclinical medical students. J Gen Intern Med. 2002;17(1):58-65.

8. Montes GS. Da implantação de uma disciplina de Iniciação Científica ao currículo nuclear na graduação em medicina na USP. Rev. Bras. Cardiol. 2000; 2(2):70-77.

9. Jacobs CD, Cross, PC. The value of medical student research: the experience at Stanford University School of Medicine. Medical Education 1995, 29: 342-346.

10. Bulcão LG, El-Kareh AC, Sayd JD. Ciência e ensino médico no Brasil (1930-1950). Hist Cienc Saúde - Manguinhos [on line] 2007; 14(2). Disponível em: http:/ / www. scielo.br/scielo.php?script=sci_arttext\&pid=S0104970 $2007000200005 \& \operatorname{lng}=$ pt\&nrm $=$ iso\&tlng $=$ pt. Acesso em: 28.07.2009.

11. Montes GS. Iniciação científica: essencial na graduação de medicina. Interação (FMUSP — São Paulo) 1997,1: 2.

12. Harasym PH, Mandim H, Sokol PA, Lorscheider FL. Development of a research elective program for first- and second-year medical students. Teaching and learning in medicine 1992, 4(3): 173-179.

13. Cardoso GP, Silva Jr CT, Netto ALCC. Dez anos de iniciação científica: o que aprendemos? Experiência da disciplina de iniciação científica do curso de medicina da UFF. Pulmão. RJ 2005; 14(2):131-66. 
14. Oliveira NA, Alves LA, Luz MR. Iniciação Científica na graduação: $\mathrm{O}$ que diz o estudante de Medicina? Rev Bras Edu Med 2008; 32(3):309-314.

15. Brasil. Ministério da Educação. Conselho Nacional de Educação. Câmara de Educação Superior. Resolução n.4, CNE/CES de 7/11/2001. Institui diretrizes curriculares nacionais do curso de graduação em medicina. Diário Oficial da União. Brasília, 9 nov. 2001; Seção 1, p. 38. Disponível em: URL: http://portal.mec.gov.br/cne/arquivos/ pedf/CES04.pdf. Acesso em: 23.07.2009.

16. Levèvre F, Levèvre AMC. O Discurso do sujeito coletivo: um novo enfoque em pesquisa qualitativa (Desdobramentos). Caxias do Sul, RS: EDUCS, 2003.

17. Kirkpatrick D L, Kirkpatrick J D. Evaluating training programs: the four levels. 3a Ed. San Francisco: Berrett-Koehler, 2006.

\section{CONTRIBUIÇÃO DOS AUTORES}

Hermila Guedes trabalhou na concepção do estudo, na aplicação dos questionários, na compilação e análise dos dados e na redação do artigo. Jorge Guedes colaborou na compilação e análise das informações e na redação do artigo.

\section{CONFLITO DE INTERESSES}

Declarou não haver.

\section{ENDEREÇO PARA CORRESPONDÊNCIA}

Hermila Tavares Vilar Guedes

Faculdade de Tecnologia e Ciências de Salvador.

Av. Luiz Viana Filho 8812

Paralela — Salvador

CEP. 41741-590 BA

E-mail: guedesh@uol.com.br 